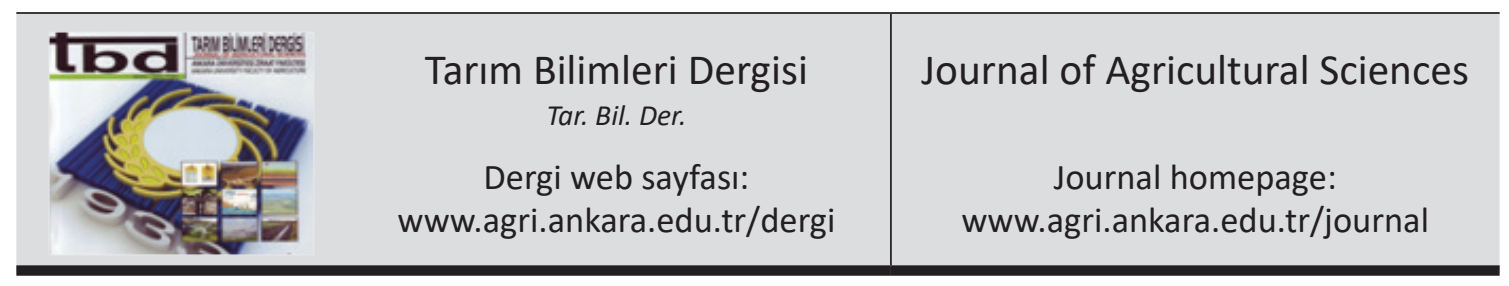

\title{
Morphological Changes Caused by Bacillus megaterium on Adult Emergence of Fall Webworm's Pupa, Hyphantria cunea (Drury) (Lepidoptera: Erebidae)
}

\author{
Hasan Murat AKSOY ${ }^{\text {, Islam SARUHAN }}$, Yilmaz KAYA ${ }^{\mathrm{b}}$, Murat OZTURK ${ }^{\mathrm{a}}$ \\ ${ }^{a}$ Ondokuz Mayis University, Agriculture Faculty, Plant Protection Department, 55139 Kurupelit, Samsun, TURKEY \\ ${ }^{b}$ Ondokuz Mayis University, Agriculture Faculty, Department of Agricultural Biotechnology, 55139 Kurupelit, Samsun, TURKEY
}

\section{ARTICLE INFO}

Research Article DOI: 10.15832 ankutbd.349474

Corresponding Author: Hasan Murat AKSOY, E-mail: hmaksoy@omu.edu.tr, Tel: +90 (362) 3121919

Received: 06 November 2017, Received in Revised Form: 18 January 2018, Accepted: 24 January 2018

\begin{abstract}
Insecticidal effects of Bacillus megaterium isolates maintained from bacterial oozed pupae were studied on pupae and $2^{\text {nd }}$ instar larvae of Hyphantria cunea. The bacterial isolates were identified according to morphological, physiological, biochemical and sequence analyses. This study reported that Bacillus megaterium isolates, HMA5 and BM1, caused different abnormal wings shapes and hair loss on thorax and abdomen of Hyphantria cunea. In addition, the HMA5 and BM1 treated pupae showed significantly reduced ability of adult emergence rates. The percentages of the adult emergence from pupae were $1 \%$ and $2 \%$ for HMA5 and BM1, respectively.
\end{abstract}

Keywords: Bacillus megaterium; Hyphantria cunea; Morphological changes

(C) Ankara Üniversitesi Ziraat Fakültesi

\section{Introduction}

Hyphantria cunea (Drury) is a moth in the family Erebidae, and a widespread pest of ornamental and fruit trees. The pest is highly polyphagous and causes economic damage due to the reduced crop yields and destroys overall productivity ( $\mathrm{Su}$ et al 2008). The life cycle of the pest consists of four different periods; adult, pupa, larva and egg. Different larval stages of the pest eat large amount of leaves, causing complete defoliation. One of the control methods against the pest is to use pesticides from different groups to prevent larval damage in plants. However, chemical control of this pest can be difficult due to their webbing, reducing the penetration of insecticides to the point that the pest may not come in contact with a lethal dose. In addition, the use of pesticides causes a negative effect on atmosphere and the development of high level pest resistance ( $\mathrm{Li}$ et al 2013). Since chemical control is harmful to the environment, biological control agents for Hyphantria cunea have been used in agricultural lands as a better approach for pest control. Bacillus thuringiensis, an entomopathogenic bacterium, has been used in biological control of Hyphantria cunea. The bacterium is an effective biocontrol agent of this pest and can be used in preference to insecticides (Zibaee et al 2010). For controlling pests, the use of another species of Bacillus, Bacillus 
megaterium, producing insecticidal metabolites is a new tool for biotechnological research (Aksoy \& Ozman-Sullivan 2008). Also the bacteria can be used as biological control agent of nematodes (Huang et al 2010). Bacillus megaterium is a rodlike, gram positive, mostly aerobic, spore forming microorganism discovered in many different types of habitat such as dried food, sea and soil (Gu et al 2007). So far there have been many reports on microorganisms as potential microbial biological control agents (Ozsahin et al 2014; Aksoy et al 2015). However, Bacillus megaterium against pupae of Hyphantria cunea were not used in these studies.

The aim of the study is to isolate bacterial isolates from diseased pupae of Hyphantria cunea in hazelnut orchards in Samsun province in Turkey, to evaluate the isolates by molecular techniques, to categorise insecticidal activity on $2^{\text {nd }}$ instar larvae of Hyphantria cunea and to evaluate efficacy of the bacterial isolates on adult emergence from Hyphantria cunea pupae. This is the first study carried out on Bacillus megaterium against pupae and larvae of Hyphantria cunea.

\section{Material and Methods}

\subsection{Insects}

Healthy pupae and $2^{\text {nd }}$ instar larvae of Hyphantria cunea were provided by Ondokuz Mayis University, Agricultural Faculty, Plant Protection Department, Entomology Lab. (Samsun, Turkey).

\subsection{Bacterial isolation}

Diseased pupae of Hyphantria cunea were randomly collected from the bark cracks of different hazelnuts orchards or in the soil of fall webworm damaged areas where have not been previously treated with any Bacillus biopesticide in Samsun province. The collected samples were kept at about $4{ }^{\circ} \mathrm{C}$ in the refrigerator until further use for bacterial isolation. To eliminate external contamination, diseased Hyphantria cunea pupae were sterilized in 1\% sodium hypochlorite solution for $3 \mathrm{~min}$. The samples were then washed three times in sterile distilled water and transferred aseptically into a sterile mortar and macerated with a sterile pestle in $1.5 \mathrm{~mL}$ of sterile distilled water. The suspension was then heated at $75{ }^{\circ} \mathrm{C}$ for $10-15$ min because non-spore isolates were eliminated. $1 \times 10^{-2}$ and $1 \times 10^{-4}$ dilutions were streaked on nutrient agar plates incubated at $30{ }^{\circ} \mathrm{C}$ for $48 \mathrm{~h}$ (Cavados et al 2001) and candidate isolates were selected based on colony morphology.

\subsection{Biochemical characteristics}

The morphological, physiological and biochemical characteristics of Bacillus isolates were determined according to Logan \& Vos (2009).

\subsection{DNA extraction}

The total genomic DNA was extracted from bacterial suspension (after $12 \mathrm{~h}$ incubation in LB) using Qiagen DNA extraction kit. DNA concentration was standardized at about $50 \mathrm{ng} \mu \mathrm{L}^{-1}$ for PCR assay.

\subsection{S rRNA gene sequencing}

$16 S$ rRNA gene region of two isolates was amplified by PCR tests for sequence analysis using the universal primers 27F (AGAGTTTGATC(AC) TGGCTCAG); positions 8 to 27 and 1492R (ACGGTTACCTTGTTACGACTT); positions 1508 to 1492, (Weisburg et al 1991). Amplifications of the $16 \mathrm{~S} r R N A$ gene were performed in a final volume of 50 $\mu \mathrm{L}$ containing $25 \mu \mathrm{L}$ of $2 \mathrm{x}$ BioMix ${ }^{\mathrm{TM}}$ Red (Bioline), $1 \mu \mathrm{L}$ of each primer, and $1 \mu \mathrm{L}$ of template DNA and $17.5 \mu \mathrm{L}$ of $\mathrm{dH}_{2} \mathrm{O}$. Reactions were performed in a BioRad T100 Thermal Cycler. The PCR conditions were $15 \mathrm{~min}$ at $94{ }^{\circ} \mathrm{C}, 35$ cycles of $30 \mathrm{~s}$ at $94{ }^{\circ} \mathrm{C}, 1 \mathrm{~min}$ at $52{ }^{\circ} \mathrm{C}$ and $90 \mathrm{~s}$ at $72{ }^{\circ} \mathrm{C}$, followed by a final extension at $72{ }^{\circ} \mathrm{C}$ for $7 \mathrm{~min}$.

Sequencing for PCR products of the selected isolates was performed in both directions, carrying out by the Medsantek Company, Turkey. The Chromas Pro Software (Technelysium Pty Ltd, Qld, Australia) was used for editing and regenerating the obtained sequences. Resulted partial $16 S$ rRNA gene sequences of Bacillus megaterium were searched in GenBank database (http://www.ncbi. nlm.nih.gov/Genbank) with available sequences using nucleotide-nucleotide Basic Local Alignment Search Tool (BLAST). Moreover, Mega 6 software 
was used for alignment analyses and also construct a phylogenetic tree (Tamura et al 2013).

\subsection{Bioassay for the pupae}

Twenty healthy pupae of Hyphantria cunea were placed in $1 \mathrm{~L}$ plastic ice-cream cups (sterilized by ethanol) containing filter papers moisturized by sterile distilled water. Twenty healthy pupae of Hyphantria cunea were put into each ice-cream cup and sprayed with a $10^{8} \mathrm{cfu} \mathrm{mL}^{-1}$ suspension of the bacterial isolates grown on nutrient agar at $30 \pm 2{ }^{\circ} \mathrm{C}$ for $24 \mathrm{~h}$. Harvested cells with a drigalski spatula suspended in sterile distilled water. The turbidity of the each bacterial suspension was adjusted to an optical density at $600 \mathrm{~nm}\left(\mathrm{OD}_{600}\right)$ of $0.7\left(10^{8} \mathrm{cfu} \mathrm{mL}^{-1}\right.$, colony-forming units $\mathrm{mL}^{-1}$ ).

The suspension was applied on pupae placed on the cups from a distance of $25-30 \mathrm{~cm}$ with a hand spray atomiser of $50-\mathrm{mL}$ capacity until the pupae surface was just wetted with very fine droplets. The negative control cups were sprayed with sterile distilled water and incubated at $24 \pm 2{ }^{\circ} \mathrm{C}$ with $65 \pm 5 \%$ relative humidity $(\mathrm{RH}), 16: 8 \mathrm{~h}$ light:dark photoperiod for 30 days in a Binder incubator (Model KBWF 240, Germany). Polyethylene sheets were used together with rubber in order to cover the open sides of cups. The pupae were checked daily to collect emerged adult. The causal agents were reisolated from the pupae according to Cavados et al (2001) and found identical to the originals cultures characterized by sequencing of $16 S$ rRNA gene.

The treatments consisted of: (i) 20 pupae of Hyphantria cunea, bacterization with Bacillus megaterium (isolate-HMA5); (ii) 20 pupae of Hyphantria cunea, bacterization with Bacillus megaterium (isolate-BM1); (iii) 20 pupae of Hyphantria cunea, bacterization with Bacillus thuriginesis (isolate-27.1a, isolated previously from soil (16S rRNA Accession Number: KX683870); (iv) 20 pupae of Hyphantria cunea were sprayed with sterile distilled water (Control-C). The bioassays were conducted twice with five replications.

\subsection{Bioassay for the $2^{\text {nd }}$ instar larvae}

Twenty $2^{\text {nd }}$ instar larvae of Hyphantria cunea were put into each $1 \mathrm{~L}$ plastic ice-cream cups (sterilized by ethanol) containing filter papers moistured by sterile-distilled water. Fresh acer leaves were sprayed with suspension of the bacterial isolates and allowed to air dry. The control leaves were treated with distilled water. The larvae were then fed on leaves treated and non-treated with suspension of the bacterial isolates. The uneaten leaves were removed every $24 \mathrm{~h}$ and the larvae were fed fresh untreated leaves. The larvae were incubated at $25 \pm 1{ }^{\circ} \mathrm{C}$ and $65 \pm 5 \%$ relative humidity $(\mathrm{RH}), 16: 8 \mathrm{~h}$ light:dark photoperiod for 10 days in a Binder incubator (Model KBWF 240; Germany) and checked every day to collect dead larvae. On the fourth day after starting the experiment mortality of larvae were recorded. The causal agents were re-isolated from dead nymphs according to Cavados et al (2001) and shown to be identical to the organisms characterized by sequencing of $16 S$ rRNA gene.

The treatments consisted of: (i) $202^{\text {nd }}$ instar larvae of Hyphantria cunea, bacterization with Bacillus megaterium, isolate HMA5; (ii) $202^{\text {nd }}$ instar larvae of Hyphantria cunea, bacterization with Bacillus megaterium, isolate BM1; (iii) 20 $2^{\text {nd }}$ instar larvae of Hyphantria cunea, bacterization with $B$. thurigiensis strain 27.1a; (iv) $202^{\text {nd }}$ instar larvae of Hyphantria cunea were sprayed with sterile distilled water (Control-C). The bioassays of larvae were conducted twice with five replications.

\subsection{Data analysis}

Kolmogorov-Smirnov One Sample Test results showed that all traits could be assumed normally distributed $(\mathrm{P}<0.05)$. Levene variance homogeneity test results indicated that all traits had homoscedasticity $(\mathrm{P}<0.05)$. Then, One-Way ANOVA test was applied to the all data, least significant difference (LSD) multiple comparison tests were used to compare the means. All analyses were evaluated using SPSS v21.0 (SPSS Inc., Chicago, IL, USA). 


\section{Results and Discussion}

\subsection{Bacterial isolation}

Two Bacillus megaterium isolates, HMA5 and BM1, with insecticidal activity were selected based on morphological physiological and biochemical characteristics.

\subsection{Biochemical characteristics}

The isolates, HMA5 and BM1, were motile, rodshaped and gram-positive. On nutrient agar, the fresh colonies were $1-2 \mathrm{~mm}$ in irregular shaped, translucent whitish, diameter, slightly convex with entire edges and smooth after $24-48 \mathrm{~h}$ at $30^{\circ} \mathrm{C}$. Both isolates showed positive results for different tests such as catalase, hydrolysis of gelatin and starch, deamination of phenylalanine, acid production from sugars such as d-glucose, l-arabinose and d-mannitol. They were negative result for vogesproskauer test. They were approved to be members of the genus Bacillus by means of the ability to form spores, gram staining and colony morphology. On the basis biochemical diagnostic tests, these isolates were identified as Bacillus megaterium.

\section{3. $16 S \mathrm{r}$ RNA gene sequencing}

The 16S rRNA sequences of these strains analyzed in the research were provided from public database (GenBank). The generated nucleotide sequences of HMA5 and BM1 were deposited in the GenBank database with accession numbers are KY231928 and KY231929, respectively.

The 16S rRNA gene sequences of HMA5 and BM1 shared $100 \%$ sequence similarity with representative Bacillus megaterium strains and the isolate $27.1 \mathrm{a}$ had $99 \%$ sequence similarity with Bacillus thuringiensis strains in the Genbank database at the nucleotid level.

\subsection{Bioassay for the pupae}

The total number of adult emerged from pupae were recorded daily for each treatment and compared with untreated control groups. The bioassay results indicated HMA5 and BM1 were highly toxic against adult emergence from the pupae. The percentages of adult emergence were in the range of $1-99.5 \%$, where they were $84.5 \pm 1.71 \%, 2.0 \pm 0.77 \%$ and $1.0 \pm 0.41 \%$ for the isolates $27.1 \mathrm{a}, \mathrm{BM} 1$ and HMA5, respectively. Bacillus megaterium isolates, HMA5 and BM1 treated pupae showed significantly reduced ability to adult emergence rates. The mean adult emergence decreased from $99.5 \pm 1.23 \%$ in the control to $1 \pm 0.41 \%$ and $2 \pm 0.77 \%$ for bacterial suspension treated with HMA5 and BM1 isolates, respectively. The mean adult emergence for the treated pupae with 27.1a also decreased, but this decrease was less than for the bacterial suspension treated with HMA5 and BM1. In contrast, the results showed a significant difference between the control and all of the samples $(\mathrm{P}<0.05)$ (Figure 1).

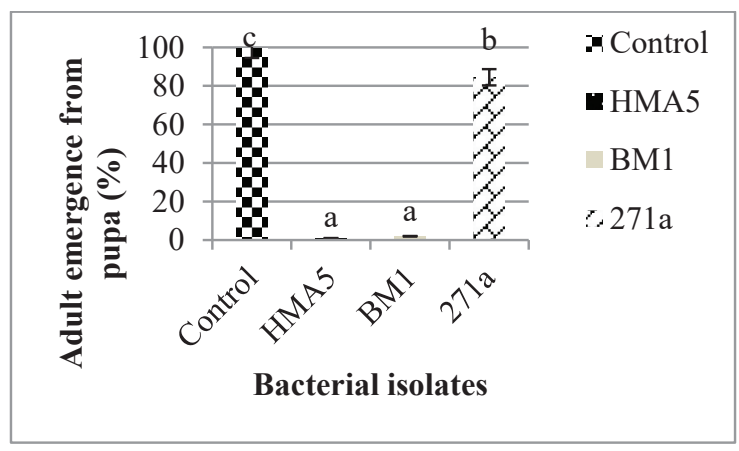

Figure 1- Effect of Bacillus megaterium isolates; HMA5, BM1 and Bacillus thuringiensis isolate 27.1a on adult emergence from the pupae (Different letters above the bars showed significiancy, $\mathrm{P}<0.05$ by LSD test)

Bacillus megaterium isolates, HMA5 and BM1, induced embryonic mortality and morphological abnormality in the adult emergence of the treated pupae. There was no morphological change in the adult emergence of control group, while HMA5 and BM1 isolates caused different wings defects and hair loss on thorax and abdomen of the adults (Figure 2). In addition, the isolates inhibited almost all adult moths from the pupae. Only few adult moths emerged from the pupae with abnormal morphological deformations (Figure 3). 


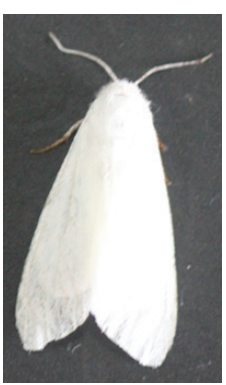

$\mathbf{a}$

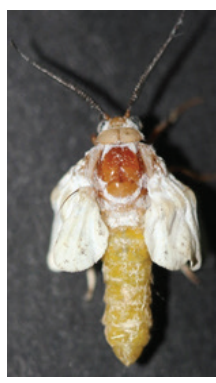

e

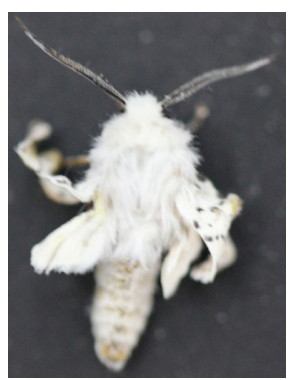

b

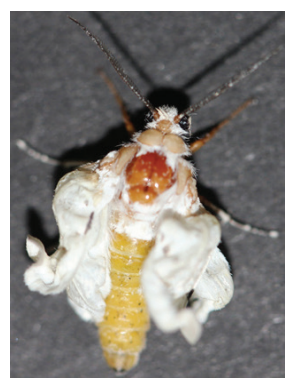

f

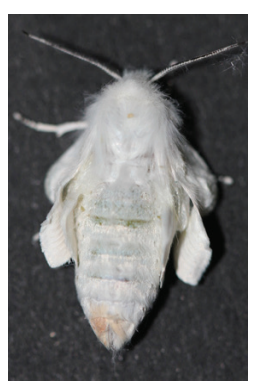

c

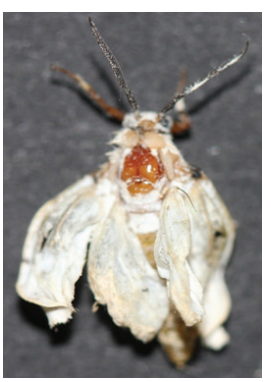

$\mathbf{g}$

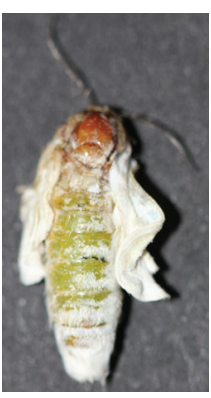

d

Figure 2- Morphological abnormality in the adult emerged from treated pupae with Bacillus megaterium isolate, HMA5. The pupae sprayed with: a, sterile water (control), healthy adult emergence; b, HMA5 isolate, adult emergence with short twisted wings; c, adult emergence with short wings and swelled abdomen; d, adult emergence with short frizzled wings and partial hair loss on thorax and abdomen; e, adult emergence with short wings and completely hair loss on thorax and abdomen; f, adult emergence with cabbage leaf form wings and completely hair loss on thorax and abdomen; g, and adult emergence with fringed wings and completely hair loss on thorax and abdomen

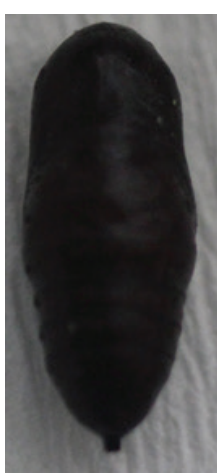

a

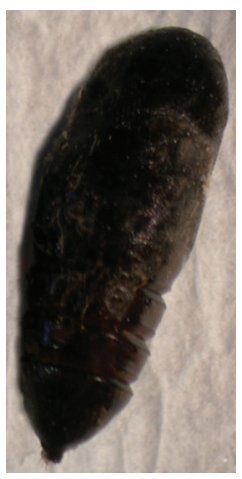

b

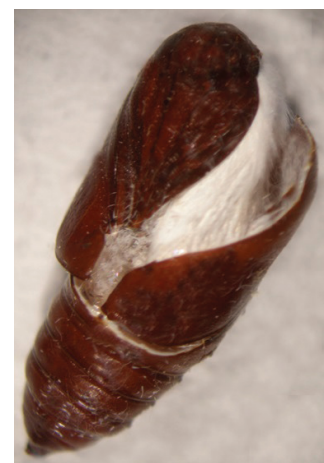

c

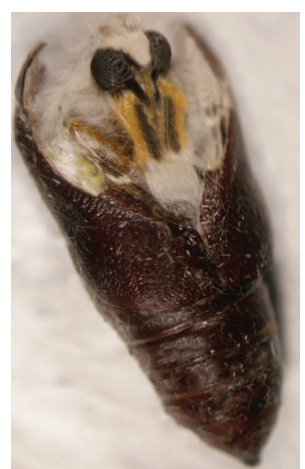

d

Figure 3- Morphological abnormality in the adult emergence of treated pupae with Bacillus megaterium isolate, HMA5. The pupae sprayed with: a, sterile water (control), healthy pupa; b, no adult emergence, diseased pupa; $c$, partial pupa cracking; $d$, and semi pupa opening 


\subsection{Bioassay for the $2^{\text {nd }}$ instar larvae}

Bacillus megaterium and Bacillus thuringiensis isolates were significantly attack the mortality of $2^{\text {nd }}$ instar larvae of Hyphantria cunea. Four days after treatment, the $2^{\text {nd }}$ instar larval mortality was $62.25 \pm 1.46 \%, \quad 59.25 \pm 3.28 \%, \quad 57.0 \pm 2.22 \%$ and $0.75 \pm 0.12 \%$ for the isolates HMA5, BM1 and $27.1 \mathrm{a}$ and control, respectively. However, the percent mortalities caused by the Bacillus megaterium isolates (HMA5 and BM1) did not show statistically significant differences $(\mathrm{P}<0.05)$. The percentage of mortality was highest for HMA5 treatment, and lowest for 27.1a treatment (Figure 4).

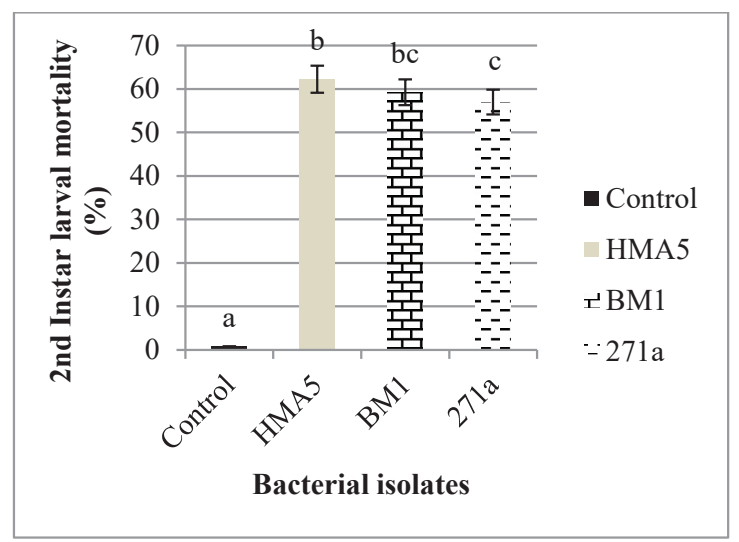

Figure 4- Mortality effect of Bacillus megaterium isolates; HMA5, BM1 and Bacillus thuringiensis isolate 27.1a on the $2^{\text {nd }}$ instar larvae of Hyphantria cunea (Within columns followed by same letters indicated no significiancy among them (LSD test $\mathbf{P}<\mathbf{0 . 0 5}$ )

The isolates, HMA5 and BM1, caused mortality with dry and blacken body of the larvae, while the isolate 27.1a caused mortality with blacken body and softness abdomen of the larvae (Figure 5).

Bacillus species including Bacillus thuringiensis, Bacillus megaterium and Lysinibacillus sphaericus have been successfully used as biological agents for controlling undesirable organims. These strains exhibit toxicity against caterpillars, beetles, and flies due to their ability to create chemically poison during sporulation (Wagner et al 1996; Berry

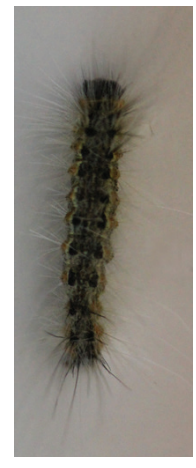

$\mathbf{a}$

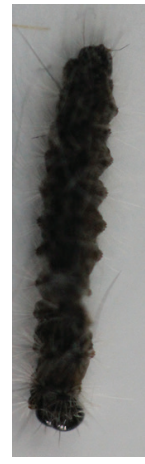

b

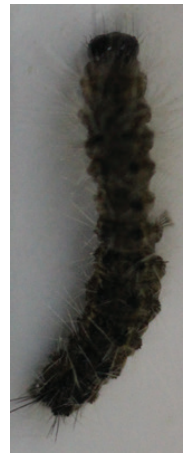

c

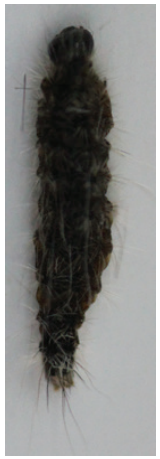

d
Figure 5- Mortality symptoms of Bacillus megaterium isolates; HMA5, BM1 and Bacillus thuringiensis isolate $27.1 \mathrm{a}$ on the $2^{\text {nd }}$ instar larvae of Hyphantria cunea: a, control; b, HMA5; c, BM and d, 27.1a

2012). Various researches have been studied on the nematicidal and insecticidal effects of Bacillus megaterium . Khyami-Horani et al (1999) reported that populations of Bacillus megaterium represents one of the best biological agent and highly toxic to the $4^{\text {th }}$ instar larvae of Culiseta longiareolata. Aksoy \& Ozman-Sullivan (2008) showed that the isolates of Bacillus megaterium were successfully used for Aphis pomi within five days of the treatments, causing $92 \%$ to $100 \%$ mortality. For nematodes, Bacillus megaterium has also been applied as bioagents. For reducing $\mathrm{J} 2$ penetration of sugar beet (Beta vulgaris L.), several bacterial isolates were successfully used against the sugar beet cyst nematode, Heterodera schachtii (Schmidt) (Neipp \& Becker 1999). In addition, to reduce $\mathrm{J} 2$ penetration of potatoes, Bacillus megaterium has been effectively applied as a biological control agent against the Columbia Root-knot nematode, Meloidogyne chitwoodi and the root-lesion nematode, Pratylenchus penetrans (Al-Rehiayani et al 1999).

In this study, the two isolates, named HMA5 and BM1 were identified based on biochemical characterization tests following Logan \& Vos (2009). HMA5 and BM1 were closely related to Bacillus megaterium and Bacillus thuringiensis. Bacillus species have similarities and some of them 
only differ in biochemical test so the determination of the species level is very difficult. However, Bacillus megaterium and Bacillus thuringiensis can be distinguished by Voges-Proskauer test; acid production from d-glucose; deamination of phenylalanine and hydrolysis of casein. Bacillus megaterium can produce acid from d-glucose and hydrolyse casein while not for Bacillus thuringiensis (Sneath 1986; Slepecky \& Hemphill 2006; Logan \& Vos 2009). Analysis of the $16 S$ $r R N A$ gene confirmed that isolates HMA5 and BM1 were Bacillus megaterium, with 100\% sequence similarity with the available Bacillus megaterium strains in Genbank database.

\section{Conclusions}

Bacillus species have been used as biological pesticides. These isolated species from diverse regions around the biosphere have been determined as several genotypes (Ben-Dov et al 1997; Xu et al 2006). Although the isolates, HMA5 and BM1 were not fully effective on larvae of Hyphantria cunea, the results showed that the Bacillus megaterium isolates caused different abnormal wings shapes and loss of hair on thorax and abdomen (Figure 2). In addition, these isolates highly inhibited adult emergence from the pupae. On the other hand, Bacillus thuringiensis isolate, 27.1a caused no abnormal morphological deformations on the pupae (Figure 4). The reason may be effective secondary metabolite(s) is/are secreted from the vegetative cells of HMA5 and BM1. Abnormal morphological deformations may occur due to the diffusion effects of these metabolites into the chitin layer. It is hypothesized that these metabolites disrupt the structure of the regulator proteins of the wings and hair on thorax and abdomen. This present study represents the first report of morphological changes on the pupae of Hyphantria cunea. Further studies are needed to clarify the active secondary metabolites affecting the healthy adult emergence from pupae to be use in broad spectrum for controlling insects and also to find out the mode of action of these secondary metabolites.

\section{Acknowledgements}

This study was supported by TUBITAK (The Scientific and Technological Research Council of Turkey) with the project number of 1130189.

\section{References}

Aksoy H M \& Ozman-Sullivan S K (2008). Isolation of Bacillus megaterium from Aphis pomi (Homoptera: Aphididae) and assessment of its pathogenicity. Journal of Plant Pathology 90: 433-436

Aksoy H M, Saruhan I \& Ozturk M (2015). Insecticidal effects of Bacillus megaterium isolates against fall webworm (Hyphantria cunea Drury, (Lepidoptera: Arctiidae). $5^{\text {th }}$ Entomopathogens and Microbial Control Congress, 9-11 September Ankara University, Ankara, Turkey, pp. 61

Al-Rehiayani S, Hafez S L \& Thornton M (1999). Effects of Pratylenchus neglectus, Bacillus megaterium, and oil radish or rapeseed green manure on reproductive potential of Meloidogyne chitwoodi on potato. Nematropica 29: 37-49

Ben-Dov E, Zaritsky A, Dahan E, Barak Z, Sinai R, Manasherob R, Khamraev A, Troitskaya E, Dubitsky A, Berezina N \& Margalith Y (1997). Extended screening by PCR for seven $c r y$-group genes from fieldcollected strains of Bacillus thuringiensis. Applied and Environmental Microbiology 63: 4883-4890

Berry C (2012). The bacterium, Lysinibacillus sphaericus, as an insect pathogen. Journal of Invertebrata Pathology 109: 1-10

Cavados C F G, Fonseca R N, Chaves Q, Rabinovitch L, \& Araujo-Coutinho C J P C (2001). Identification of entomopathogenic Bacillus isolated from Simulium (Diptera, Simuliidae) larvae. The Memórias do Instituto Oswaldo Cruz 96: 1017-1021

Gu Y Q, Zhou J P, Mo M H \& Zhang K Q (2007). Evaluation and identification of potential organic nematocidal volatiles from soil bacteria. Soil Biology and Biochemistry 39: 2567-2575

Huang Y, Ma L, Xu C, Zhang K, Duan C \& Mo M (2010). Characterisation of volatiles produced from Bacillus megaterium YFM3.25 and their nematicidal activity against Meloidogyne incognita. The European Journal of Plant Pathology 126: 417-422

Khyami-Horani H, Katbeh-Bader A, \& Mohsen Z H (1999). Isolation of endospore-forming bacilli toxic to 
Culiseta longiareolata (Diptera: Culicidae) in Jordan. Letters in Applied Microbiology 28: 57-60

Li J, Chen J \& Cai P (2013). Research progress of occurrence and comprehensive control of fall webworm [Hyphantria cunea (Drury)]. Plant Diseases and Pests 4: 32-44

Logan N A \& Vos D P (2009). Genus I. Bacillus Cohn 1872. In: Bergey's Manual of Systematic Bacteriology, $2^{\text {nd }}$ Ed., Vol. 3. New York: Springer

Neipp P W \& Becker J O (1999). Evaluation of biocontrol activity of rhizobacteria from Beta vulgaris against Heterodera schachtii. Journal of Nematology 31: 5461

Ozsahin E, Sezen K, Demir I \& Demirbag Z (2014). Bacterial isolates from Palomena prasina (Hemiptera: Pentatomidae) include potential microbial control agents. Biocontrol Science and Technology 24: 10391051

Slepecky R A \& Hemphill H E (2006). The genus Bacillus-nonmedical. In: Dworkin M, Falkow S, Rosenberg E, Schleifer K (eds): The Prokaryotes. $A$ Handbook of the Biology of Bacteria. Springer, New York 530-555

Sneath P H A (1986). Endospore-forming gram positive Rods and Cocci. 1104-1105 In: Sneath, P H A, N S Mour, M E Sharpe, and J G Holt (Eds). Bergy's Manual of Systematic Bacteriology, $8^{\text {th }}$ edition, 2, William \& Wilkins. Baltimore
Su M W, Fang Y L, Tao W Q, Yan G Z \& Ma W E (2008). Identification and field evaluation of the sex pheromone of an invasive pest, the fall webworm Hyphantria cunea in China. Chinese Science Bulletin 53: 555-560

Tamura K, Stecher G, Peterson D \& Kumar S (2013). MEGA 6 Molecular Evolutionary Genetics Analysis Version 6.0. Molecular Biology and Evolution 30: 2725-2729

Wagner D L, Peacock J M, Carter J L \& Talley S E (1996). Field assessment of Bacillus thuringiensis on nontarget Lepidoptera. Environmental Entomology 25: 1444-1454

Weisburg W G, Barns S M, Pelletier D A \& Lane D J (1991). 16S ribosomal DNA amplification for phylogenetic study. Journal of Bacteriology 173: 697-703

Xu J, Qin L, Yin X \& Zhu S (2006). A review of recent development of Bacillus thuringiensis ICP genetically engineered microbes. Entomology Journal of East China 15: 53-58

Zibaee, I, Bandani A R, Sendi J J, Talaei H R \& Kouchaki B (2010). Effects of Bacillus thuringiensis var. kurstaki and medicinal plants on Hyphantria cunea Drury (Lepidoptera: Arctiidae). Invertabrata Survival Journal 7: 251-261 